\title{
Organizational Performance Consequences of Age Diversity: Inspecting the Role of Diversity-Friendly HR Policies and Top Managers' Negative Age Stereotypes
}

\author{
Florian Kunze, Stephan Boehm and Heike Bruch \\ University of St Gallen
}

ABSTRACT This paper seeks to advance the diversity literature by investigating organizational performance consequences of age diversity. Drawing from social-identity and socialcategorization theory, we theoretically argue that, in age-diverse companies, age-based subgrouping processes occur, favouring a shared perception of a negative age-discrimination climate. This perceived negative age-discrimination climate in turn negatively relates to organizational performance. As the main contribution, top managers' negative age-related stereotypes and diversity-friendly HR policies are introduced as organizational-level moderators that increase and attenuate, respectively, the social categorization processes affecting performance in age-diverse companies. We utilized structural equation modelling (SEM) to test the proposed hypotheses using a multisource dataset comprising 147 companies. The results supported all hypotheses, indicating that low negative top managers' age stereotypes as well as high diversity-friendly HR policies are potential organizational factors that can prevent the negative relation of age diversity with organizational performance transmitted through the negative age-discrimination climate. These results are discussed in light of their contribution to the diversity literature and social-categorization theory as well as their implication for practitioners.

Keywords: age discrimination, age diversity, age stereotypes, diversity-friendly HR-practices, social identity theory, structural equation modelling

\section{INTRODUGTION}

The demographic changes occurring in most industrialized countries present an urgent challenge for many organizations today. Companies are confronted with the fact that their workforce is getting both older and more age diverse due to the aging of their employees and shortages in the labour pool (Baltes and Finkelstein, 2011; Dychtwald et al., 2004). These changes imply that companies who have historically had a largely

Address for reprints: Florian Kunze, Institute for Leadership and Human Resource Management, University of St Gallen, Dufourstrasse 40a, CH-9000 St Gallen, Switzerland (florian.kunze@unisg.ch). 
homogenous, young workforce have to integrate an increasing number of older employees, which in turn creates an increasingly age-diverse labour force. Consequently, the pressing question for practitioners in companies as well as from a theoretical perspective concerns the consequences of an accumulating age-diverse workforce on the company's overall performance and which organizational intervention strategies may influence it.

The results from existing empirical studies are scarce and not too encouraging so far. At the team level, a recent meta-analysis reported overall negative consequences of age diversity on team performance (Joshi and Roh, 2009). At the organizational level, some econometric studies have recently investigated the relationship between age diversity and firm performance in large-scale samples, with mixed results ranging from non-significant (Ilmakunnas et al., 2004), over inversely U-shaped (Grund and Westergaard-Nielsen, 2008), to positive (Ilmakunnas and Ilmakunnas, 2011) and negative relationships (Backes-Gellner and Veen, 2009). From an organizational behaviour perspective, a limited number of studies have reported a negative relationship between age diversity and company performance (Kunze et al., 2011 ; Leonard and Levine, 2003). In addition, research on the linkage between top management's age composition and firm performance reports varying findings, ranging from negative effects (Simons et al., 1999), over nil effects (Bantel and Jackson, 1989), to positive effects in a simulation study (Kilduff et al., 2000). These mixed findings call for a more detailed theoretical and empirical inspection of the behavioural and attitudinal mechanisms that explain the age diversity/company performance relationship in organizations.

This study will provide an additional step along these lines by theoretically arguing that - not only in teams (Ries et al., 2010), but also in whole organizations - high levels of age diversity are leading to social fragmentation between different age groups, fostered by social identity (Tajfel and Turner, 1986) and social categorization processes (Turner, 1985), which may then lead to increased levels of discriminatory behaviour between different age subgroups impairing organizational performance (Kunze et al., 2011).

As the main contribution, however, we will investigate two organizational factors namely, negative age stereotypes of the top management and diversity-friendly humanresource (HR) policies - that might aggravate and attenuate, respectively, the social-identity and social-categorization processes negatively affecting performance in age-diverse organizations. First, negative age stereotypes held by the top management are expected to play a crucial contextual role in the development of negative age subgrouping processes in organizations. The role modelling and sense-giving role of the top management (Carmeli, 2008) might induce a spillover effect of their negative age stereotypes, negatively affecting organization-wide attitudes concerning age. Consequently, processes of age subgrouping might intensify, leading to the formation of a negative age-discrimination climate that in turn negatively relates to organizational performance.

Second, we assume that the existence (respectively, non-existence) of diversity-friendly human resource (HR) practices is an important factor for the potential evolvement and nature of social fragmentation effects based on age diversity in organizations. In particular, we think that such diversity-friendly policies should help create an environment that fosters mutual respect for and among all employees, regardless of their age 


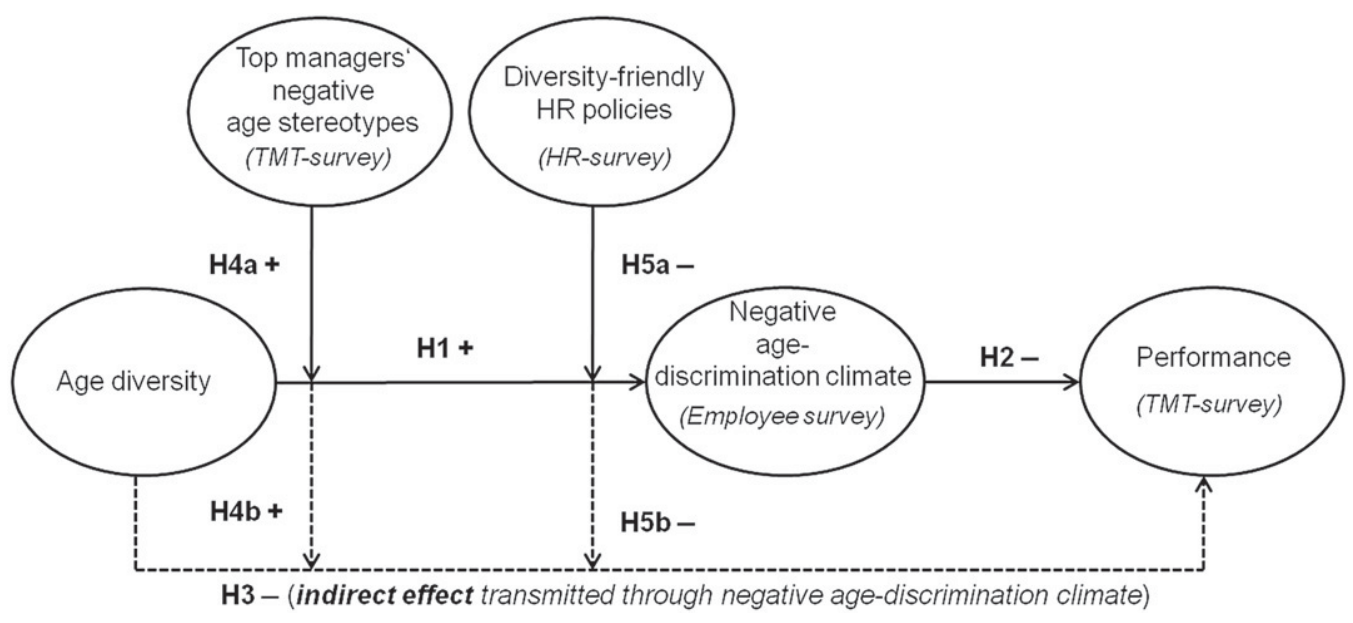

Figure 1. Theoretical model for the organizational-level relationship between age diversity and performance

Note: Data sources in parentheses and italics.

(Hicks-Clarke and Iles, 2000). In such organizations, the emergence of opposing age groups that discriminate against each other and, in turn, hinder performance should be less likely.

With this research we strive to advance theory development and integration within the field of diversity research. First, by applying the theoretical lens of the social-identity and social-categorization framework, we take these theories and diversity research to a new level, namely, the organization. That should help sharpen our understanding of age diversity as an organizational level facet and thereby extend the diversity literature that has almost exclusively focused on group-level conceptualizations of diversity and related effects (e.g. van Knippenberg and Schippers, 2007). Second, we integrate the literature on age diversity with literature on top management teams (e.g. Carmeli, 2008), age stereotypes (e.g. Posthuma and Campion, 2009), and diversity-friendly policies and practices (e.g. Triana and García, 2009; Triana et al., 2010) to create a theoretical framework that explains, based on social-categorization arguments, how to at least prevent the negative performance consequences of an age-diverse workforce. Third, beyond theoretical contributions, this research also offers important practical implications by providing companies with recommendations on how to better manage the organizational consequences of an age-diverse workforce. Figure 1 offers an overview of our conceptual model.

\section{HYPOTHESES DEVELOPMENT}

Age diversity is a collective property present in almost all collective entities, such as families, sport teams, and work groups with members of varying ages. Only recently have scholars started to investigate age as a source of diversity processes and outcomes at the organizational level of analysis (e.g. Ilmakunnas and Ilmakunnas, 2011; Kunze et al., 
2011). The mixed findings of these studies propose that age diversity is not likely to have direct consequences on company performance; instead, age diversity is likely to influence subtle and implicit processes and states within companies, which in turn potentially relate to performance outcomes. As detected at the team level (e.g. Wegge et al., 2012), processes of age subgroup formation (Tajfel and Turner, 1986) might also occur at the organizational level, inciting subgroup competition and subsequently social fragmentation (Garcia-Prieto et al., 2003; Kunze et al., 2011).

\section{Age Diversity and Negative Age-Discrimination Climate}

Although early studies defined negative age discrimination as systematic stereotyping against older people (Butler, 1969), today it is defined more broadly as age-related discrimination against both younger and older employees (Duncan et al., 2000; Snape and Redman, 2003). Only recently have Kunze et al. (2011) conceptualized negative age discrimination as an organizational climate variable that reflects employees' shared perception of the fairness - and, alternatively, unfairness - of age-related organizational behaviours, actions, and procedures towards different age groups. Building upon this definition, we assume that a shared perception of negative organizational agediscrimination climate can stem from both unfair organizational processes and systems (e.g. the firm's HR system) as well as from interpersonal interactions and events (e.g. between employees or between employees and supervisors).

In age-diverse companies, an intensified negative age-discrimination climate can be explained primarily by social identity (Tajfel and Turner, 1986) and social categorization arguments (Turner, 1985). In such age-heterogeneous companies, compared to agehomogenous organizations, age is likely to become a more salient factor of social categorization, as reported by Wegge et al. (2011) for age diverse teams.

Moreover, according to arguments based on similarity-attraction theory (Bryne, 1971), same-aged colleagues attract each other and consequently group together based on both similar stages in their private lives (e.g. having young children) and historically generated similarities (e.g. growing up in the internet age) (Lawrence, 1988). This social categorization based on age triggers more professional (e.g. going for a joint lunch, trying to work together on similar projects) as well as private interactions (e.g. joined sports and other leisure activities) between similarly aged peers. Consequently, age-based subgroups might develop that are not limited to work group or department boundaries, but can spread throughout the organization. For example, Zenger and Lawrence (1989) found that age similarity leads to more liking and better communication not only within a work group, but also between employees of the same age from different work groups within an organization. In addition, Ferris et al. (1993) argued that political networks within organizations often consist of organization-wide coalitions based on similarity on demographics such as age. Thus, 'lumpy' (Zenger and Lawrence, 1989, p. 354) age distributions within entire organizations might enable age-based subgrouping within and across groups and departments. Consequently, even if a certain group or department within a company is characterized by a largely homogenous age distribution (i.e. mostly younger employees), the few minority group members (i.e. older employees) will still try to interact 
with same-aged peers from other groups and departments, creating the potential for age-based categorization processes at the organizational level.

Ample research dating back to Tajfel's (1970) minimal group studies has demonstrated that the emergence of subgroups in collective entities almost automatically leads to in-group favouritism and out-group discrimination - namely, individuals tend to favour members of their own group (e.g. older employees) over members of other groups (e.g. younger employees). In the presence of such groupings, a drop in social integration might occur; in addition, mutual feelings of age-based discrimination might emerge throughout the organization. For example, supervisors and/or colleagues might not aim to provide a fair allocation of tasks between different age groups, but favour their own age subgroup over others. Moreover, career opportunities or peer and/or supervisor performance assessments might be heavily age-biased within companies that are split up into several age groups. In general, if the social integration between different age groups is low, age-biased practices, procedures, and behaviours become more acceptable in the organization, culminating in an overall climate of age discrimination.

The social fragmentation in age-diverse companies might be further intensified as age diversity could lead to a violation of career timetables (Lawrence, 1984). This concept assumes that clear expectations exist within organizations regarding which types of jobs or positions should be held by which age groups. Especially for employees who tend to lag 'behind schedule' or who 'do not fit their jobs', perceptions of discrimination might occur as these employees struggle with lower performance ratings and less professional development opportunities (Lawrence, 1988; Tsui et al., 2002). Feelings of age discrimination might be more pronounced in age-heterogeneous organizations that are more likely to produce situations in which such career norms are violated for both younger staff (e.g. older employees staying until the legal retirement age and blocking others' career paths) and older personnel (older employees being led by significantly younger supervisors).

If older and younger employees constantly perceive age-based discrimination within in their organization, it is very likely that this perception is not limited to the individual level; but rather, through processes of contagion (Salanova et al., 2005) and socialization (Schneider, 1987), it might spread throughout the entire organization, cumulating in high levels of shared perceptions of a negative age-discrimination climate. Thus, we assume the following hypothesis:

Hypothesis 1: Age diversity is positively related to shared perceptions of a negative age-discrimination climate in companies.

\section{Negative Age-Discrimination Climate and Company Performance}

In companies in which employees perceive high levels of a negative age-discrimination climate incited by the social fragmentation of an age-diverse workforce, the company's overall performance might suffer. Drawing from social exchange theory (Blau, 1964), we argue that employees who perceive age discrimination at the workplace are likely to respond with lower levels of emotional attachment, which in turn negatively affects corporate performance. In order to preserve a distinct willingness to contribute to 
organizational goals and ultimately to organizational performance, employees have to perceive a fair and mutual exchange relationship with their organization (Hutchison et al., 1986; Shore and Wayne, 1993). As the perception of age discrimination can be regarded as a clear breach of such a 'norm of reciprocity' (Gouldner, 1960), drops in collective motivation and ultimately in performance seem likely. From an empirical point of view, Hassell and Perrewe (1993) have shown such a decline in organizational attachment among employees who perceived age discrimination in their organization. Similarly, Snape and Redman (2003) found a negative relation between the experience of age discrimination and the level of affective commitment for both young and old employees.

Such feelings of being undervalued by the organization might also emerge as a collective phenomenon within whole companies. Concerning sex discrimination, numerous studies have described the emergence of feelings of 'collective relative deprivation' (Tougas and Veilleux, 1989, p. 122) experienced by people who feel that their own group (e.g. their gender group) is systematically disadvantaged while the other group is favoured (Gutek et al., 1996). Building on the salience of age as a category for the social identity of employees, Snape and Redman (2003) concluded that the concept of collective relative deprivation could be applied to age groups. Consequently, if younger and/or older employees receive the impression that members of their age group are constantly disadvantaged due to their age, they might develop a collective sense of relative deprivation, which in turn leads to drops in collective commitment, job involvement, and ultimately overall company performance. In sum, we propose the following hypothesis:

Hypothesis 2: Shared perceptions of a negative age-discrimination climate are negatively related to company performance.

Summarizing the relationships described above, we can conclude that age diversity does not directly relate to company performance, but rather indirectly does through an increase in the climate of age discrimination. In age-heterogeneous companies, social categorization processes take place that advance the emergence of age subgroups, leading to perceived discrimination on the basis of age. Such perceived age discrimination might, in turn, negatively affect overall company performance as employees respond with lower levels of collective commitment and joint effort focused on company goals. Consequently, we propose the following mediation hypothesis:

Hypothesis 3: Shared perceptions of negative age-discrimination mediate the indirect relationship between age diversity and company performance.

\section{Moderators of the Negative Indirect Relationship between Age Diversity and Company Performance}

The negative indirect effect of age diversity previously described is assumed to be contingent upon two other organizational factors. First, we expect negative age stereotypes of top management to exacerbate the relationship between age diversity and negative age discrimination climate. Second, we expect diversity-friendly HR policies to attenuate this relationship. 


\section{Top Managers' Negative Age Stereotypes as a Moderator}

First, we propose that the relation between age diversity and negative age-discrimination climate depends upon top managers' negative age stereotypes against older workers. Work-related age stereotypes are individual beliefs and expectations about employees that are merely based on their age group membership (Hamilton and Sherman, 1994). While age stereotypes in theory can refer to any age group, existing research in the management area (Posthuma and Campion, 2009), as well as in gerontology (Levy et al., 2012) and social psychology research (O'Brien and Hummert, 2006), has primarily investigated stereotypes against older individuals. In consequence, we also focus on stereotypes against older workers. Such prevalent negative age stereotypes include the beliefs that older workers are less motivated and show decreased performance (Abraham and Hansson, 1995; Shore and Wayne, 1993), have a lower ability to learn (Brooke and Taylor, 2005; Wrenn and Maurer, 2004), and are more costly for companies (Capowski and Peak, 1994; Ostroff and Atwater, 2003). Although empirical research has demonstrated that most of these stereotypes are unfounded (e.g. Kanfer and Ackerman, 2004; Posthuma and Campion, 2009), many employers still hold to these stereotypes (European Commission, 2009). They are a relevant problem for the successful management of age diversity as they might intensify the perceptions of general age discrimination at the workplace (Posthuma and Campion, 2009).

Although age-related stereotypes of any organizational member might lead to an increase of age categorization processes they might be especially harmful if held by top managers. The reason for this potential to spur age-categorization processes lies in the basic tenets of upper echelons theory, which proposes that organizations are reflections of their top managers (Hambrick and Mason, 1984). More specifically, this theory assumes that top managers have important sense-giving and sense-making functions (Maitlis, 2005) for the organization as their employees perceive and interpret how their management acts, then adapt their own behaviour accordingly. Consequently, top managers' attitudes and behaviours are interpreted as desired behaviours among employees (Carmeli, 2008). Concerning our assumed relationship, employees can for example observe recruiting and promotion decisions that the top management makes and determine whether age plays a relevant role. Are employees who are over 40 already regarded as too old for high potential programmes? Do employees over 50 still have the chance to move from middle to top management ranks? As stereotypes are an important antecedent of related behaviour (Fiske, 2004), negative age stereotypes held by the top management increase the likelihood that many such decisions and behaviours show a certain form of age bias or even age discrimination. Furthermore, employees might evaluate the communication and speech of top management members in terms of their age bias. For example, do the top managers attribute the company's low or high performance to a certain age group of employees? Are specific younger or older employees recognized for their performance?

These attitudes and behaviours are, in turn, expected to affect the age-based socialidentity and social-categorization processes taking place in age-diverse companies. If top management holds negative stereotypes about a certain age group (e.g. older employees), it indicates to employees that categorization and discrimination based on age are 
appropriate and accepted behaviours in the company. Thus, in companies with high negative age stereotypes held by the top management, employees might even be implicitly encouraged to show unfair behaviour towards their colleagues and/or subordinates from opposing age groups, inciting more age discrimination and consequently lowering overall performance.

In contrast, in organizations in which the top management does not hold negative age stereotypes, age in general should be regarded as less important for the classification and differentiation among employees, thereby mitigating the effect of age diversity on a negative age-discrimination climate. Thus, we propose the following moderation hypothesis:

Hypothesis 4a: Negative age stereotypes of the top management moderate the relationship between age diversity and shared perceptions of the negative age-discrimination climate in companies, such that the relationship is positive when top managers have high levels of negative age stereotypes and not significant when top managers have low levels of negative age stereotypes.

Based on the theoretical reasoning for the mediating role of the negative agediscrimination climate on the relationship between age diversity and performance (see Hypothesis 3), we assume that the top management's negative age stereotypes may also play an important context role for the indirect relationship between age diversity and performance. If top managers' low age stereotypes make it less likely that age becomes a salient criterion for subgrouping and related discriminatory behaviour throughout the company, not only should the relationship between age diversity and the negative age-discrimination climate disappear, but the negative age-discrimination climate will also lose its role as a mediator between age diversity and company performance. In contrast, if high levels of top management's negative age stereotypes spur age-based subgrouping and negative discrimination throughout the company, the mediating role of a negative age-discrimination climate between age diversity and performance should also increase. Consequently, we propose the following hypothesis:

Hypothesis 4b: Top management's negative age stereotypes moderate the indirect and negative relationship between age diversity and company performance mediated by shared perceptions of the negative age discrimination climate, such that the indirect relation is negative when top managers have high levels of negative age stereotypes and not significant when top managers have low levels of negative age stereotypes.

\section{Diversity-Friendly HR Policies as a Moderator}

Second, we assume that the relation between age diversity and the negative age discrimination climate is dependent upon diversity-friendly HR policies. Both scholars and practitioners have repeatedly emphasized the need to actively manage and foster diversity within organizations (e.g. Robinson and Dechant, 1997; Thomas and Ely, 1996) in order to fully exploit its opportunities while avoiding its potential challenges (Horwitz and Horwitz, 2007; van Knippenberg and Schippers, 2007). One way to achieve this is 
for organizations to adopt practices (e.g. trainings, workshops, leadership development programmes) to promote and value diversity as a core focus of the organization (Triana and García, 2009; Triana et al., 2010). As Triana and García (2009) explained, such diversity-friendly HR policies (often also labelled as efforts to support diversity) effectively demonstrate to employees that the organization shows respect and provides equal opportunities for all its members, irrespective of their demographic attributes (e.g. race, gender, age).

Consequently, even if employees perceive certain forms of age discriminatory treatment at the individual level (e.g. by certain colleagues or supervisors), it is less likely that they will generalize such incidents and perceive the organization as generally age discriminatory. In other words, under conditions of high diversity-friendly HR policies, employees are more likely to perceive their employer as age-neutral, just, trustworthy, and upstanding (Triana and García, 2009; Triana et al., 2010). In those companies with high diversity-friendly HR policies, the negative social categorization processes triggered by age diversity, such as subgroup formation and perceived violation of career timetables, are less likely to surface, allowing at least a zero relationship between age diversity and the negative agediscrimination climate. If employees perceive that their organization values diversity through its practices and activities, they might transfer these practices to their own behaviour and avoid discriminatory behaviour towards colleagues or subordinates from dissimilar age groups. In other cases, under conditions of low diversity-friendly HR policies, individually experienced incidents of age discrimination triggered by the processes of age subgroup formation might easily lead to the formation and perception of a strong firm-wide climate of age discrimination. Thus, we propose the following hypothesis:

Hypothesis 5a: Diversity-friendly HR policies moderate the relationship between age diversity and shared perceptions of the negative age-diversity climate such that the relationship is positive at low levels of diversity-friendly $\mathrm{HR}$ policies and not significant at high levels of diversity-friendly HR policies.

Referring back to the theorized mediating role of shared perceptions of the negative age-discrimination climate for the relationship between age diversity and performance that we proposed in Hypothesis 3, we assume that diversity-friendly HR policies are also crucial for the existence or non-existence of an indirect relation between age diversity and company performance. In companies that have a diversity supportive work environment, negative social-fragmentation processes based on age-group memberships leading to discrimination are unlikely to occur very often. Consequently, the negative age-discrimination climate also loses its role as a mediator between age diversity and performance and the indirect relationship is likely to vanish. In contrast, if diversityfriendly HR policies are less present in companies, the mediating role of the agediscrimination climate is strengthened. In this condition, employees do not perceive any support by their employer to reduce age-based discrimination. In sum, we propose the following mediated-indirect hypothesis:

Hypothesis 5b: Diversity-friendly HR policies moderate the indirect and negative relationship between age diversity and company performance mediated by a shared 
perception of the negative age-discrimination climate in companies, such that the indirect relation is not significant when high levels of diversity-friendly HR policies are present and negative when low levels of diversity-friendly HR policies are present.

\section{METHODS}

\section{Sample}

For this study, we collected data in German small and medium-sized companies in two successive years. Overall 202 companies applied voluntarily to participate in the research project that was part of a larger benchmarking study in cooperation with a professional agency from Germany. As a reward for their participation, companies received an extensive benchmarking report. Due to dropouts the final sample comprised 147 companies, reflecting an organizational response rate of 73 per cent. Participating companies came from different types of industries $(52$ per cent $=$ service; 23 per cent $=$ production; 16 per cent $=$ trade; 10 per cent $=$ finance and insurance) and varied in size from 8 to 4133 employees $($ median $=127)$.

To circumvent concerns of a common method bias (Podsakoff et al., 2003), we obtained data for our study from three different sources: an employee survey, a survey of the top management team, and a survey of the head of HR.

First, all employees were asked to participate in the present study. They received an e-mail from the HR department that described the study purpose and contained the link to a web based survey hosted by an independent IT company. Overall, 30,101 of the invited employees (within-organization response rate of 68 per cent; $\mathrm{SD}=23$, range $=19-100$ per cent) participated in the study ${ }^{\left[{ }^{[1]}\right.}$ All surveyed employees were asked to provide demographic information (e.g. their individual age). To limit the amount of questions each employee had to answer for the overall benchmarking report, employees were randomly assigned to one of four different versions of the employee survey. In our study, we used only one of these four employee surveys that contained the items assessing the negative age-discrimination climate. The items for this scale were thus answered by randomly selected 25 per cent of the employees from each company. On average, the participating employees were 38 years old, had been with their company for 10 years, and were mostly male (58 per cent). The average age of the sample almost matches the average age of the German workforce of 40 years (Börsch-Supan and Wilke, 2009), which strengthened our confidence to have a largely representative sample of companies.

Second, we asked the members of the top management to assess their age stereotypes as well as the company performance. They were also invited to participate in the study by an e-mail from the HR department. Overall, 491 top managers participated in the study, ranging from 1 to 14 participants per company. The within-organization response rate was 74 per cent $(\mathrm{SD}=28$; range $=14-100$ per cent). Responding top managers were on average 47 years old, had been with the company for 11 years, and were mostly male (85 per cent).

Finally, the head of HR from each company was asked about the diversity-friendly HR policies by the company as well as about the company size, industry affiliation, as well as other control variables (environmental dynamism, limited labour supply, inno- 
vation capacities)..$^{[2]}$ The top HR managers were on average 44 years old, had been with the company for 12 years, and were mostly male (64 per cent).

\section{Measures}

If not otherwise noted, all measures were assessed on a 7-point Likert scale $(1=$ strongly disagree; $7=$ strongly agree). The detailed wording of all items is provided in the Appendix.

Age diversity. To create our age diversity measure, we used the individual responses from all employees about their age in absolute years. The standard deviation of age was taken to measure the age diversity within companies. This procedure was applied following the suggestion of Harrison and Klein (2007) that the operationalization of a diversity measure should be determined by its conceptualization. Diversity can be conceptualized in terms of disparity, variety, and separation. While the first two are referring to compositional differences in valued assets (disparity) or relevant experiences (variety), the latter describes differentiation processes in collective entities due to social categorization processes (separation). With our theoretical reasoning, we clearly apply separation arguments with social identity and similarity-attraction mechanisms. Consequently, we used the standard deviation as the most commonly applied measure for operationalizing diversity as separation (Harrison and Klein, 2007). ${ }^{[3]}$

Negative age-discrimination climate $(\alpha=0.97$, composite reliability $(C I)=0.99)$. We measured negative age-discrimination climate using the 5 -item scale recently applied and validated by Kunze et al. (2011). This measure inquires about several occasions that can be a source of age discrimination in companies. To justify the aggregation of individual responses, we relied on common aggregation statistics, such as intra-class correlation coefficients $\left(\mathrm{ICC}_{1}\right.$ and $\mathrm{ICC}_{2}$; Bliese, 2000) and the average deviation index as an interrater agreement measure $\mathrm{AD}_{\mathrm{M}()}$ (Burke et al., 1999). Concerning the aggregation of the age discrimination scale, we received sufficient results for all statistics $\left(\mathrm{ICG}_{1}=0.05\right.$, $\left.\mathrm{ICG}_{2}=0.68, \mathrm{p}<0.001, \mathrm{AD}_{\mathrm{M}(J)}=0.84\right) \cdot{ }^{[4]}$

Negative top managers' age stereotypes ( $\alpha=0.80, C I=0.88$ ). The age stereotypes of the top management were measured by three items drawn from the age stereotype scale developed by Chiu et al. (2001). Due to space restrictions in the top management survey, we chose the items that were most directly referring to behaviours of older employees (see Appendix). The individual attitudes of the top managers were averaged at the organizational level if more than one top manager had responded $(n=116)$. Since we treated this measure as a pure aggregate (averaging the personal stereotypes of each individual top manager) and not as a compositional organizational level construct (e.g. we do not assume a shared consensus of the top managers on stereotypes), we did not calculate aggregation statistics.

Diversity-friendly $H R$ policies ( $\alpha=0.91, C I=0.95)$. Top HR representatives of each company were inquired about diversity-friendly HR policies. We used three out of five 
items from the organizational efforts to support diversity (OESD) scale developed by Triana and García (2009) that directly addressed pro-diverse HR practices. The other two items from the original OESD scale refer to a general appreciation of diversity by the company and not concrete practices and were therefore not used for this study. Since all items refer to institutional diversity management efforts by the companies, we think that the HR representatives should be valuable key-informants (Avery and McKay, 2010).

Company performance ( $\alpha=0.81, C I=0.78$ ). Members of the top management were asked to report on the company's performance. In line with Combs et al. (2005), we defined company performance as consisting of both organizational and operational performance dimensions. For operational performance, we used two items relating to employee productivity, as well as employee retention and fluctuation. To assess organizational performance, we used two items relating to the current financial situation and company growth as indicators. All four performance items were assumed to load on one common performance factor. Following prior studies (Wall et al., 2004), the subjective performance measure was benchmarked by asking the top managers to evaluate the performance of their company compared to their direct industry rivals on a 7 -point scale $(1=$ far below average; $7=$ far above average). For those companies in which more than one top manager $(\mathrm{n}=116)$ answered, aggregation statistics justified the aggregation to the organizational level $\left(\mathrm{ICC}_{1}=0.31, \mathrm{ICC}_{2}=0.61 \mathrm{p}<0.001, \mathrm{AD}_{\mathrm{M}(\mathrm{J})}=0.43\right)$.

Controls. We controlled for several factors that might bias our results. First, we accounted for the mean age of employees in our analyses to address the argument put forth by Finkelstein et al. (1995), who advocate that age discrimination in companies might be diminished if older workers become an integral part of companies. Second, we controlled for the average age difference between employees and the top management to account for the argument that a relatively 'young' top management team might be perceived as a violation of organizational career timetables (Lawrence, 1984), thereby increasing the negative age-discrimination climate. Third, we included organization size as control variable, since prior research has shown that it relates to numerous behaviours and attitudes within companies (Pierce and Gardner, 2004). We log transformed this variable because of the skewed distribution. Fourth, we entered a dummy variable $(0=$ year $1 ; 1=$ year 2$)$ into the model to account for the year in which the information about each company was gathered because, for example, a different economic environment in a specific year might affect the overall company performance. Fifth, we asked top HR representatives to evaluate three variables that might function as omitted variables in the age structure/company performance relation - namely, limited labour supply, environmental dynamism, and companies' innovation capacities - thereby limiting the risk of endogeneity (Aubert and Crepon, 2006; Goebel and Zwick, 2009) in our model. Finally, we also controlled for four classes of industry affiliation (i.e. production, service, trade, and finance and insurance). 


\section{Analytical Techniques}

We tested our study hypotheses applying structural equation modelling (SEM) techniques with the statistical package AMOS 18. Following the recommendation of Anderson and Gerbing (1988), we tested the measurement structure and the structural relationships in two separate steps.

As our hypotheses included both moderation and mediation effects, we had to apply different techniques. In order to investigate the moderation effects (Hypotheses $4 \mathrm{a}$ and 5a), we followed the recommendations by Little et al. (2006). In particular, we used orthogonal centred product terms of the latent construct to model the interactions in our structural model. To better interpret the interactions, we also did a graphical plotting of the results and simple slope testing, as proposed by Aiken and West (1991) based on regression analyses. The indirect effect (Hypotheses 3) and indirect-moderated effects (Hypotheses 4b and 5b) were tested in SEM by applying bootstrapping procedures, as proposed by Cheung and Lau (2008). Following the description of regression analysis by Preacher et al. (2007), we specified alternative models in SEM with high values of the moderators $(+1$ standard deviation) and low values of the moderators $(-1$ standard deviation) to investigate the conditional indirect effects with bootstrapping techniques. Finally, as a further robustness check for our results, we employed an instrumental variable approach (e.g. Staiger and Stock, 1997) with 2-stage-least-square (2SLS) estimation techniques (e.g. Greene, 2008) to replicate our results.

\section{RESULTS}

Table I illustrates the intercorrelations between the study's constructs. As expected, age diversity within companies related positively to negative age-discrimination climate $(\mathrm{r}=0.28, \mathrm{p}<0.001)$, and negative age-discrimination climate related negatively with company performance $(r=-0.23, p<0.01)$. Negative age stereotypes of the top management related negatively with organizational performance $(r=-0.26, p<0.01)$. Regarding the control variables, mean age related negatively with negative agediscrimination climate $(\mathrm{r}=-0.16, \mathrm{p}<0.05)$ and with company performance $(\mathrm{r}=-0.20$, $\mathrm{p}<0.05)$. The companies' innovation capacities related negatively with negative agediscrimination climate $(\mathrm{r}=-0.17, \mathrm{p}<0.05)$ and positively with company performance $(\mathrm{r}=0.20, \mathrm{p}<0.05)$. Out of the industry controls only trade showed a positive relation to negative age-discrimination climate $(r=0.16, \mathrm{p}<0.05)$.

\section{Measurement Model}

The measurement model consisted of four latent constructs: negative age-discrimination climate, negative age stereotypes of the top management, diversity-friendly HR policies, and company performance measured with 15 items overall and the single item measure of age diversity.

To evaluate the overall model fit, we chose three different fit indices: the comparative fit index (CFI), the incremental fit index (IFI), and the root mean square error of approximation (RMSEA). This procedure follows the recommendation by Bentler 


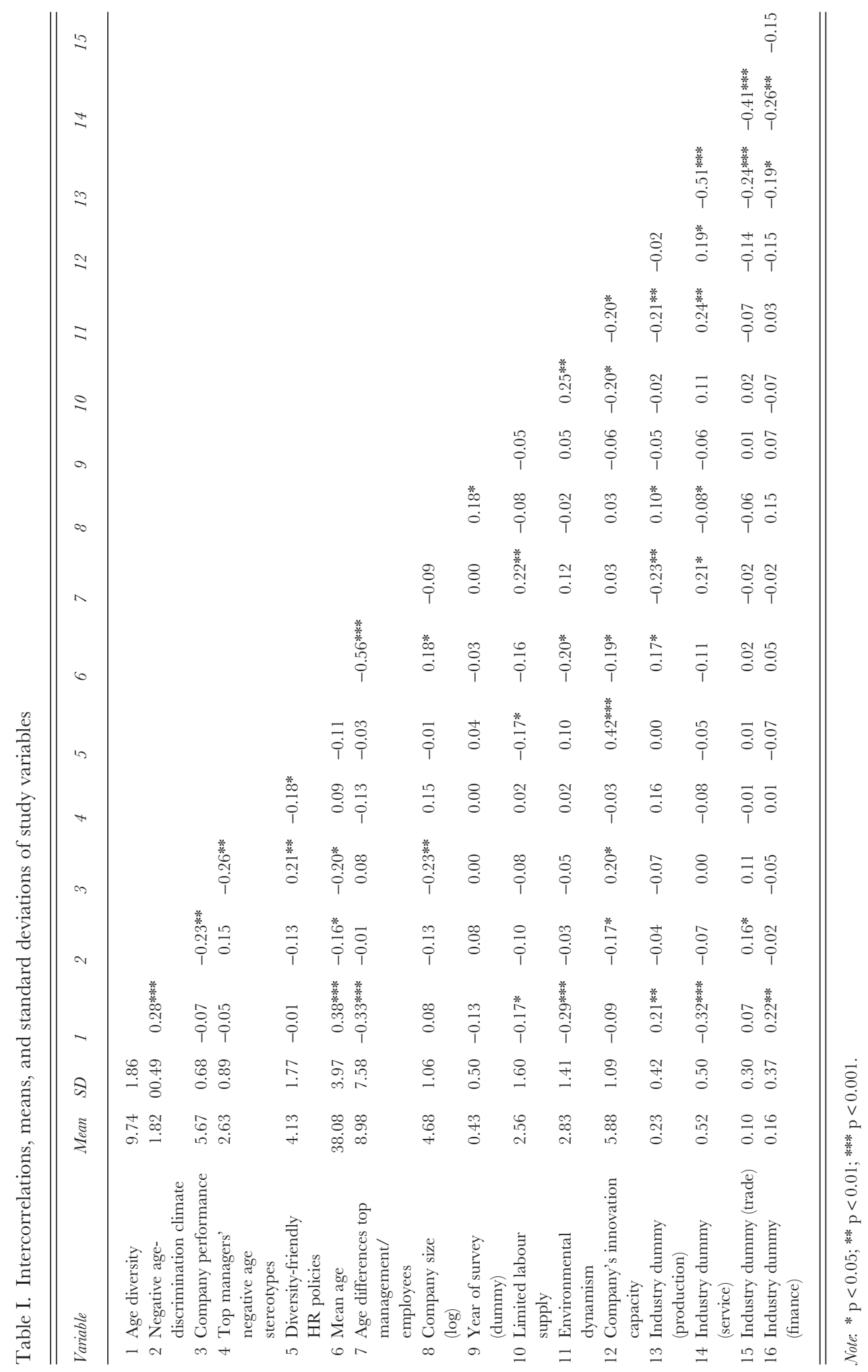


(2007), who suggested that for small samples, such as ours, the RMSEA in combination with two incremental fit indices should be reported. Commonly applied cut-off values for the IFI and CFI are values $>0.90$ (e.g. Hu and Bentler, 1998) and $<0.08$ for the RMSEA to indicate sufficient model fit (Browne and Cudeck, 1993). Concerning our measurement model, we obtained sufficient values for all three indices $\chi^{2}=138$, d.f. $=96$; $\mathrm{CFI}=0.97, \mathrm{IFI}=0.97, \mathrm{RMSEA}=0.056)$. Additionally, all factor loadings were above 0.40, a threshold often applied in factor analysis (Hulland, 1999) and significant on at the 5 per cent level (see also Figure 2). As shown in Table II, we also compared the measurement model to four alternative models. First, a four-factor model in which the age discrimination and age stereotype items loaded on one common factor (alternative model 1) had a significantly worse fit $\left(\Delta \chi^{2}=139 ; \mathrm{p}<0.001\right)$. Second, a three-factor model with the diversity-friendly $\mathrm{HR}$ policies, the age discrimination and age stereotype items loading on one factor (alternative model 2) was worse fitting $\left(\Delta \chi^{2}=424 ; \mathrm{p}<0.001\right)$. Third, a two-factor model with also age diversity loading on the prior specified common factor (alternative model 3) fitted worse $\left(\Delta \chi^{2}=424 ; \mathrm{p}<0.001\right)$. Finally, a one-factor model (alternative model 4$)$, with all items loading on one common factor was worse fitting $\left(\Delta \chi^{2}=492\right.$; $\mathrm{p}<0.001)$.

\section{Structural Model}

In the second step of our analysis, we investigated the structural relationships specified in the theory section of this paper. In line with Richardson and Vandenberg (2005), we specified paths from the control variables to all dependent study constructs. Additionally, we also allowed a direct relationship between age diversity and performance.

The overall results of the moderated-indirect model indicate a good fit of the hypothesized model to the data $\left(\chi^{2}=354\right.$, d.f. $=247$; $\mathrm{CFI}=0.95$, IFI $\left.=0.96, \mathrm{RMSEA}=0.052\right)$. None of the six alternative models had a superior fit compared to the moderated-indirect model, as shown in Table II. First, a direct-effect only model (alternative model 1), which only allowed for a direct relationship between age diversity and company performance, had a worse fit $\left(\Delta \chi^{2}=8 ; \mathrm{p}<0.01\right)$. Second, a mediation-only model (alternative model 2) that allowed all structures of the moderated-indirect model, but restricted the effects of the two interaction terms to zero had a worse fit $\left(\Delta \chi^{2}=6 ; \mathrm{p}<0.05\right)$. Third, also a no-controls model (alternative model 3 ) that allowed all structural relations of the moderated-indirect model but the paths to the control variables were set to zero showed worse global fit properties $\left(\Delta \chi^{2}=59 ; \mathrm{p}<0.001\right)$. Fourth, a moderation-only model (alternative model 4 ) that was analogous to the moderated-indirect model but the relationship between negative age-discrimination climate and performance was restricted to zero did not show superior fit properties $\left(\Delta \chi^{2}=3 ; \mathrm{p}=\mathrm{ns}\right)$. Finally, a reversed-causality model (alternative model 5) that reversed the direction of influence for the age diversity/age discrimination and the age discrimination/performance relationship did not show a superior fit $\left(\Delta \chi^{2}=1 ; \mathrm{p}=\mathrm{ns}\right)$ (Table III).

In the moderated-indirect model, the path coefficients were concurrent with our theoretical expectations (see Figure 2), thus all our hypotheses received support. As proposed in Hypothesis 1 , age diversity related positively to negative age-discrimination climate in companies $(\beta=0.18, \mathrm{t}=2.21, \mathrm{p}<0.05)$. We also observed the expected 


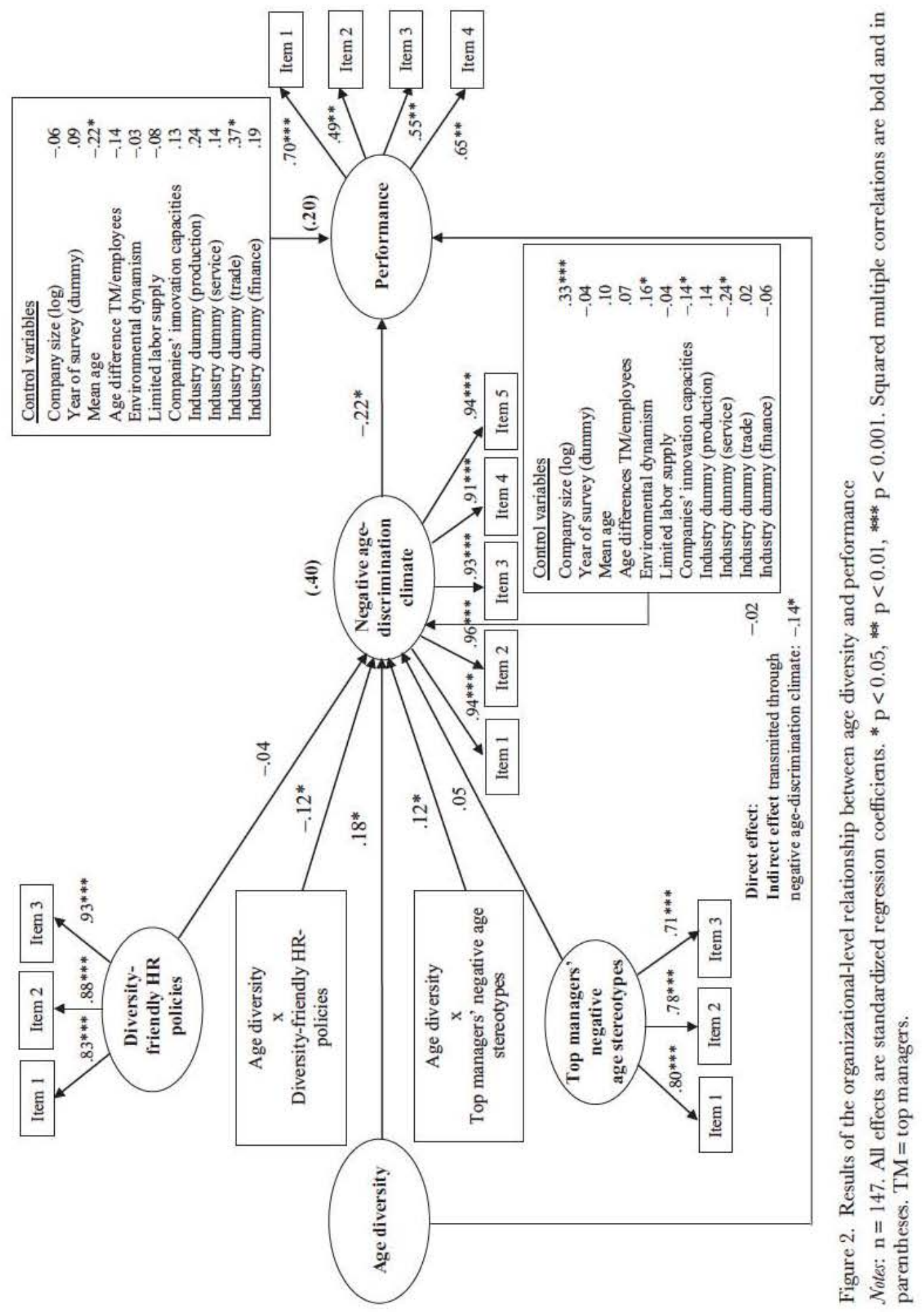


Table II. Measurement model comparison

\begin{tabular}{lrrrrrrrrr}
\hline \hline Model & $\chi^{2}$ & $d f$ & $\chi^{2} / d f$ & $\Delta \chi^{2}$ & & $\Delta d f$ & $C F I$ & IFI & RMSEA \\
\hline Hypothesized model: Five factor & 138 & 96 & 1.44 & & & & 0.97 & 0.97 & 0.056 \\
Alternative model 1: Four factor & 277 & 99 & 2.80 & 139 & $* * *$ & 3 & 0.88 & 0.88 & 0.115 \\
Alternative model 2: Three factor & 562 & 102 & 5.51 & 424 & $* * *$ & 6 & 0.70 & 0.69 & 0.180 \\
Alternative model 3: Two factor & 562 & 103 & 5.46 & 424 & $* * *$ & 7 & 0.70 & 0.70 & 0.180 \\
Alternative model 4: One factor & 630 & 104 & 6.06 & 492 & $* * *$ & 8 & 0.65 & 0.65 & 0.192 \\
\hline \hline
\end{tabular}

Notes: $\mathrm{n}=147$; CFI = Comparative Fit Index; IFI = Incremental Fit Index; RMSEA = Root Mean Squared Error of Approximation. All measurement models are compared to the hypothesized model. $* * * \mathrm{p}<0.001$.

Table III. Structural model comparison

\begin{tabular}{lrlllllllll}
\hline \hline Model & $\chi^{2}$ & $d f$ & $\chi^{2} / d f$ & $\Delta \chi^{2}$ & & $\Delta d f$ & CFI & IFI & RMSEA \\
\hline Hypothesized model: Moderated indirect & 354 & 247 & 1.43 & & & & 0.95 & 0.96 & 0.052 \\
Alternative model 1: Direct effect only & 362 & 249 & 1.45 & 8 & $* *$ & 2 & 0.95 & 0.95 & 0.056 \\
Alternative model 2: Mediation only & 360 & 249 & 1.45 & 6 & $*$ & 2 & 0.94 & 0.95 & 0.057 \\
Alternative model 3: No controls & 413 & 269 & 1.54 & 59 & $* * *$ & 22 & 0.93 & 0.93 & 0.063 \\
Alternative model 4: Moderation only & 357 & 248 & 1.44 & 3 & + & 1 & 0.95 & 0.95 & 0.057 \\
Alternative model 5: Reversed causality & 355 & 247 & 1.44 & 1 & + & 0 & 0.95 & 0.95 & 0.056 \\
\hline \hline
\end{tabular}

Notes: $\mathrm{n}=147$; CFI = Comparative Fit Index; IFI = Incremental Fit Index; RMSEA = Root Mean Squared Error of Approximation. All structural models are compared to the hypothesized model.

+ Indicates that the moderated-indirect model was more parsimonious.

*** $\mathrm{p}<0.001 ; * * \mathrm{p}<0.01 ; * \mathrm{p}<0.05$ chi-difference statistic compared to the hypothesized model.

negative effect between negative age-discrimination climate and company performance $(\beta=-0.22, t=-1.74, p<0.05)$ that was proposed by Hypothesis 2 . The direct path between age diversity and performance was non-significant, suggesting a fully indirect relationship. Since both the relationship between age diversity and negative agediscrimination climate as well as the relationship between negative age-discrimination climate and company performance were significant, we carried out bootstrapping procedures as proposed by Cheung and Lau (2008) to test Hypothesis 3. The results from 1000 bootstrapping samples showed a significant indirect relation between age diversity and company performance via the transmission of negative age-discrimination climate $(\beta=-0.14 ; \mathrm{SE}=0.08 ; 90$ per cent confidence intervals (bias accelerated $)=-32-0.04)$ and thus confirmed our expectation.

Additionally, negative age stereotypes of the top management $(\beta=0.12, \mathrm{t}=1.64$, $\mathrm{p}<0.05)$ and diversity-friendly $\operatorname{HR}$ policies $(\beta=-0.12, \mathrm{t}=-1.64, \mathrm{p}<0.05)$ had the proposed moderating effect on the age diversity/negative age-discrimination climate relationship following our predictions from Hypotheses $4 \mathrm{a}$ and $5 \mathrm{a}$. To further inspect the moderating effects, we did a graphical plotting of the results with 1 standard deviation above and below the mean values of the moderators that are illustrated in Figures 3 and 


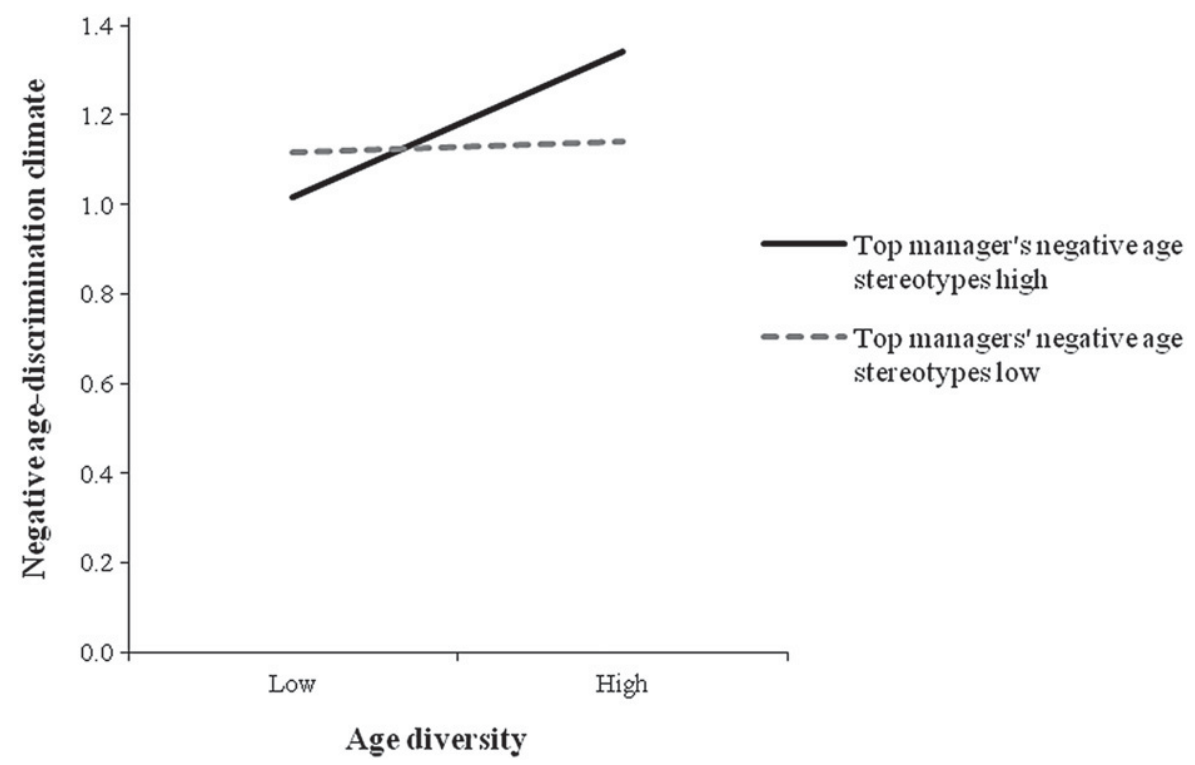

Figure 3. Top managers' negative age stereotypes moderation

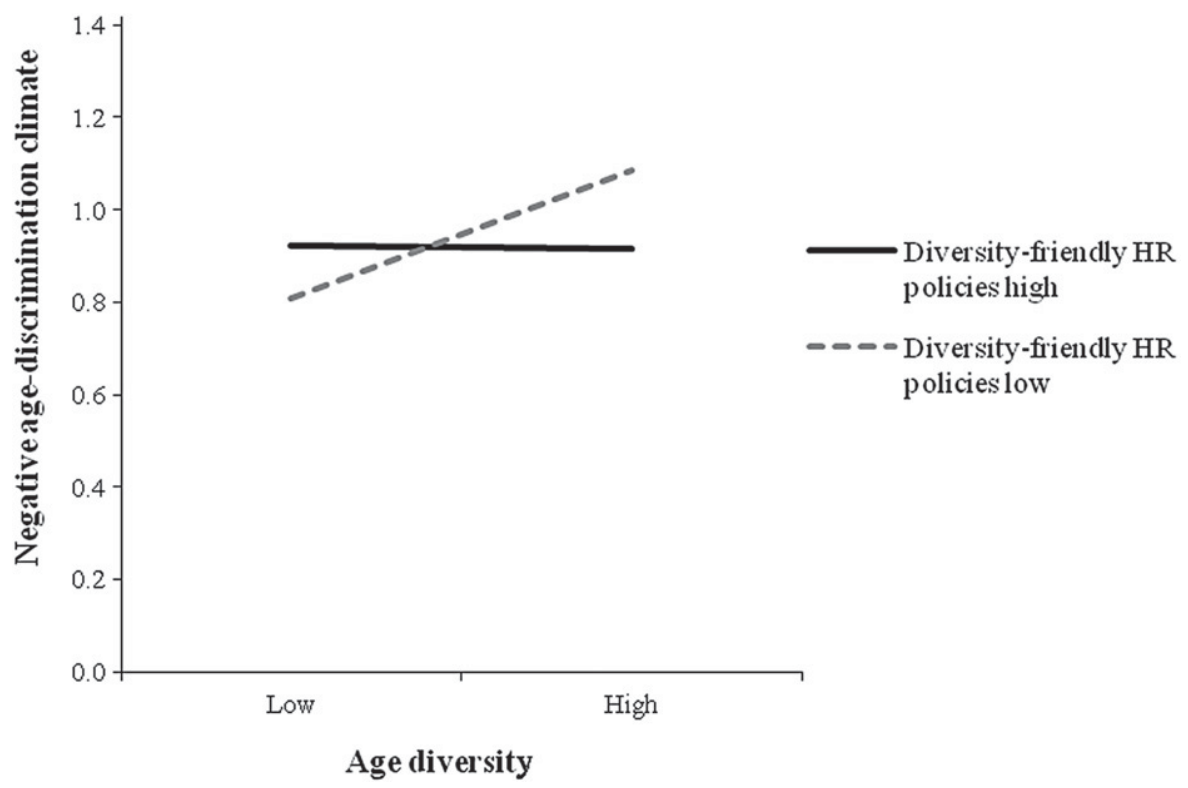

Figure 4. Diversity-friendly HR policies moderation

4. These pictures further substantiate our two moderating hypotheses. Concerning the age stereotype moderation, we observed a strong positive effect between age diversity and negative age-discrimination climate under the condition of high negative top management age stereotypes, whereas under the condition of low negative top management 
Table IV. Conditional indirect effects of age diversity on company performance under different values of top managers' age stereotypes

\begin{tabular}{|c|c|c|c|c|c|}
\hline \multirow[t]{3}{*}{$\begin{array}{l}\text { Values of the moderator (top } \\
\text { managers' age stereotypes) }\end{array}$} & \multicolumn{2}{|c|}{$\begin{array}{l}\text { Bootstrapped point } \\
\text { estimates }\end{array}$} & \multirow[t]{3}{*}{$\begin{array}{l}\text { Significance } \\
\text { level }\end{array}$} & \multirow{2}{*}{\multicolumn{2}{|c|}{$\begin{array}{c}\begin{array}{c}\text { Bootstrapped confidence intervals } \\
\text { (bias corrected) }\end{array} \\
\text { Perc. } 90 \% \text { CI }\end{array}$}} \\
\hline & \multirow[t]{2}{*}{ Boot } & \multirow[t]{2}{*}{$S E$} & & & \\
\hline & & & & Lower & Upper \\
\hline+1 standard deviation & -0.068 & 0.049 & 0.036 & -0.169 & -0.003 \\
\hline Mean & -0.042 & 0.034 & 0.039 & -0.114 & -0.001 \\
\hline-1 standard deviation & -0.013 & 0.031 & 0.238 & -0.080 & 0.025 \\
\hline
\end{tabular}

Note: 1000 bootstrapping samples were used. $\mathrm{SE}=$ standard error; $\mathrm{CI}=$ confidence interval.

age stereotypes, age diversity seemed to be almost unrelated to age-discrimination climate (see Figure 2). A simple slope test with regression techniques supported this argumentation by showing a significant positive high top management age stereotype slope $(\beta=0.15, \mathrm{t}=2.58, \mathrm{p}<0.01)$, whereas the low top management age stereotype slope turns out to be non-significant $(\beta=0.03, t=0.49, p=n s)$. For the diversity-friendly HR policies moderation (Figure 3), we observed a positive linkage for the condition of low diversity-friendly HR policies, whereas under conditions of high diversity-friendly HR policies, we observed an almost zero relation. Simple slope analyses indicated that the low diversity-friendly HR policies slope is positive and significant $(\beta=0.16, t=2.48$, $\mathrm{p}<0.01$ ), whereas the high diversity-friendly $\mathrm{HR}$ policies slope is non-significant $(\beta=0.02, \mathrm{t}=0.32, \mathrm{p}=\mathrm{ns})$.

Finally, we also tested the conditional indirect effect of age diversity on company performance under different conditions of the moderators as proposed in Hypotheses 4b and $5 \mathrm{~b}$. Therefore we ran separate models for each moderator that tested the indirect effect between age diversity and company performance under three different values of each moderator $(-1$ standard deviation, mean, +1 standard deviation). The results are depicted in Tables IV and V. They generally support the assumed moderated-indirect relationship for both organizational context factors. As Table IV shows, in line with Hypothesis $4 \mathrm{~b}$, the indirect relationship between age diversity and company performance is significant only under high values of negative age stereotypes of the top management but non-significant under the low top management age stereotypes condition. In line with Hypothesis 5b, Table V indicates that under the condition of low diversity-friendly HR policies the indirect relationship between age-diversity and performance is negative, whereas under conditions of high diversity-friendly HR policies the indirect effect is non-significant. Regarding the control variables, the most interesting finding is that mean age is negatively related to company performance $(\beta=-0.22, \mathrm{t}=-1.65, \mathrm{p}<0.05)$.

\section{Controlling for Endogeneity}

Based on the econometric research on the relationship between the age structure of the firm and productivity (e.g. Goebel and Zwick, 2009; Skirbekk, 2008), one potential risk 
Table V. Conditional indirect effects of age diversity on company performance under different values of diversity-friendly HR policies

\begin{tabular}{|c|c|c|c|c|c|}
\hline \multirow[t]{3}{*}{$\begin{array}{l}\text { Values of the moderator } \\
\text { (diversity-friendly HR policies) }\end{array}$} & \multicolumn{2}{|c|}{$\begin{array}{l}\text { Bootstrapped point } \\
\quad \text { estimates }\end{array}$} & \multirow[t]{3}{*}{$\begin{array}{l}\text { Significance } \\
\text { level }\end{array}$} & \multirow{2}{*}{\multicolumn{2}{|c|}{$\begin{array}{c}\begin{array}{c}\text { Bootstrapped confidence intervals } \\
\text { (bias corrected) }\end{array} \\
\text { Perc. } 90 \% C I\end{array}$}} \\
\hline & \multirow[t]{2}{*}{ Boot } & \multirow[t]{2}{*}{$S E$} & & & \\
\hline & & & & Lower & Upper \\
\hline+1 standard deviation & -0.019 & 0.029 & 0.140 & -0.087 & 0.013 \\
\hline Mean & -0.040 & 0.033 & 0.034 & -0.112 & -0.002 \\
\hline-1 standard deviation & -0.099 & 0.070 & 0.027 & -0.244 & -0.009 \\
\hline
\end{tabular}

Note: 1000 bootstrapping samples were used. SE = standard error; CI = confidence interval.

is that our results are biased by endogeneity issues, such as common method variance, measurement error, or omitted variables (e.g. Antonakis et al., 2010). Through our research design and several analyses, we tried to control for such a bias in multiple ways. First, we used three unique data sources (employees, HR representatives, and top management team members) to limit high common-method variance between our study constructs as one potential source of endogeneity (Antonakis et al., 2010). Second, by using SEM techniques, we controlled for the measurement error of our variables, which might be a further source of endogeneity (Antonakis et al., 2010). Third, omitted variables might also have caused endogeneity problems for our analysis. To control for this, we primarily inserted covariates (limited labour supply, environmental dynamism, and companies' innovation capacities) that prior research on the age-structure/firm productivity relationship has identified as potential sources for endogeneity (Aubert and Crepon, 2006; Goebel and Zwick, 2009).

Although these measures can control for large sources of endogeneity, some potential bias might still exist in our analyses. Therefore, we performed a final robustness check by replicating our results with 2SLS estimation techniques. In this 2SLS model we used all control variables that showed a significant correlation to age diversity (i.e. mean age, age differences between top management/employees, limited labour supply, environmental dynamism, production, service, and finance) as endogenous instrumental variables. We first inspected the F-statistics $(15.16 ; \mathrm{p}<0.001)$ and the $\mathrm{R}^{2}$ value $(0.10)$ and found them to be above the threshold for a risk of weak instrument issues (Stock et al., 2002). We then saved the predicted values of the 2SLS analysis and used them to replace the agediversity variables in the SEM analyses. The results indicated that all our assumed relationships remained significant and in the expected direction, when using the 2SLS instead of the standard maximum-likelihood estimators. These results further confirm our confidence that endogeneity is not a main issue biasing our results.

\section{DISCUSSION}

The goal of our study was to gain more insights into firm level performance effects of age diversity. Arguing from a social identity and social categorization perspective we 
assumed a negative indirect relationship from organizational-level age diversity to company performance, transmitted through negative age-discrimination climate. Using a sample of 147 companies, we found empirical support for this relationship. Higher levels of age diversity were positively related to higher levels of perceived negative age-discrimination climate, which in turn negatively affected company performance.

In order to better understand this relationship, and maybe more importantly, in order to find ways to prevent the negative age categorization processes leading to age discrimination and a drop in performance, we investigated two organizational factors as moderators. First, top managers' negative age stereotypes against older workers were proposed to moderate this relationship such that the indirect effect was expected to be significant at high levels of top managers' negative age stereotypes but non-significant at low levels of top management negative age stereotypes. Our data supported this relationship. Second, diversity-friendly HR policies were proposed to buffer the age diversity/performance relationship such that the indirect effect was expected to be significant at low levels of diversity-friendly HR policies but non-significant at high levels of diversity-friendly HR policies. Again, our data supported this hypothesis, indicating that in organizations, which carry out diversity-related efforts, age diversity does not relate to heightened levels of age discrimination climate and reduced levels of performance.

\section{Theoretical Implications}

The theorizing and empirical results of this study are an important step forward in explaining the thus far inconclusive results regarding the potential effect of organizational age structure on performance from both organizational behaviour (e.g. Kunze et al., 2011) and econometric research (e.g. Skirbekk, 2008).

First and foremost, our results indicate that social-identity and social-categorization processes might play an important role in explaining the detrimental consequences of age diversity, as previous studies have shown not only at the group level (e.g. van Knippenberg and Schippers, 2007), but also at the organizational level of analysis. We empirically demonstrated that one distinct process triggered by age-based categorization - namely, negative age-based discrimination - is more widely perceived in companies with high age diversity rather than low age diversity. As a result, our study is another step following the work of Kunze et al. (2011) to extend the argumentation of social-identity (Tajfel and Turner, 1986) and social-categorization processes (Turner, 1985) triggered by age diversity to the organizational level of analysis. Thus, we confirmed the basic rationale of these classical group theories for a new level of analysis as well.

Another main theoretical contribution of this study was to investigate organizational factors that might influence the negative social-categorization processes in age-diverse companies. To this end, we integrated different streams of literature (e.g. top management teams, stereotyping, and diversity management) with the social categorization perspective on age diversity in order to create a coherent theoretical model for explaining the consequences of age diversity in organizations.

As a first organizational factor, we explored the role of top managers' negative age stereotypes of older workers in the age diversity/performance link and complemented findings from literature streams on upper echelons (Hambrick and Mason, 1984) and age 
stereotyping (Posthuma and Campion, 2009) with social identity and socialcategorization explanations for age-diversity processes in companies. We showed that top mangers and especially their stereotypes with regard to older workers are a significant context factor for explaining if age diversity is inciting social-categorization processes that lead to higher levels of a perceived negative age-discrimination climate. This finding might be relevant for both the age diversity literature, which is extended by showing a new mechanism to aggravate or buffer detrimental social identity processes, and the literature on top management teams that centres around the question of how top managers affect organizational processes and outcomes. Although many studies have explored the link between top management teams' demographic composition and performance (e.g. Bantel and Jackson, 1989; Hambrick et al., 1996) as well as the link between top management teams' processes and performance (e.g. Carmeli and Schaubroeck, 2006; Smith et al., 1994), the role of top managers' attitudes - more specifically, their stereotypes - in processes leading to company performance has to our knowledge not been explicitly addressed to date. Our study makes a first step in this promising direction and draws from theories on signalling (Miller and Triana, 2009) and sense-making (Maitlis, 2005) to explain the cascading contextual effect of top management age stereotypes on the discriminatory behaviour of lower levels in the organization.

As a second organizational factor, we focused on the role of diversity-friendly HR policies as a specific way to create a diversity-friendly environment in which perceptions of discrimination triggered by age-subgroup processes should be significantly lower. Building upon work by Triana and García (2009), we showed that diversity-friendly HR policies are an appropriate intervention strategy for preventing the emergence of age discrimination perceptions based on social-categorization processes in companies. By doing so, we also contributed to the developing field of diversity management and diversity-friendly HR policies research in several ways. One the one hand, as requested by Triana and García (2009, p. 956), we showed that diversity-friendly HR policies are not only an effective way to tackle racial discrimination, but their effects may also 'generalize to gender or age discrimination'. On the other hand, we examined the effects of diversity-friendly HR policies at the organizational level of analysis across different companies. This might be an important finding for the diversity literature in general, which repeatedly called for an empirical examination of the 'business case' for diversity initiatives and investigation of whether such measures differentiate performance among firms (Avery and McKay, 2010). Interestingly, we found that diversity-friendly HR policies decrease the negative relationship between age diversity and firm performance, despite the fact that these practices are targeted towards a general diversity-friendly climate and not a specific age-diversity climate. Age-inclusive HR practices, targeting the specific needs of all age groups within companies (e.g. Armstrong-Stassen, 2008; Goebel and Zwick, 2010) might potentially intensify the moderating effect. Consequently, we encourage the inclusion of such age-inclusive measures in future studies as they might help achieve positive performance consequences of age diversity in organizations.

Finally, although the relationship between age diversity and company performance was our main interest in this study, interestingly we also discovered a negative main effect of mean age on company performance, indicating support for the often mentioned negative performance stereotype for older workers (Posthuma and Campion, 2009). Thus, our 
study also adds to prior studies investigating the effect of mean age on productivity (see Skirbekk, 2008, for an overview). However, these results have to be interpreted with caution as we did not use sophisticated estimator approaches for that relationship, as was done in other studies (e.g. Aubert and Crepon, 2006; Goebel and Zwick, 2009), to rule out endogeneity issues. Nonetheless, it might be a worthwhile endeavour to also inspect the mean age/performance relationship in more detail in future studies and, for example, examine age-adjusted HR practices (e.g. Goebel and Zwick, 2010) that might help to at least buffer negative firm performance consequences of an aging workforce.

\section{Practical Implications}

Our results imply several important indications for companies in light of the demographic change. Primarily, the results provide a further cue that age diversity is bound to trigger higher levels of perceived negative age discrimination within companies, which in turn negatively affects overall performance outcomes. As a first implication, companies should hence regularly assess the age composition of their workforce (Jonker and Ziekemeyer, 2005) to develop a sense of awareness and evaluate whether increased age diversity and age discrimination is a potential obstacle for performance.

If high levels of age diversity are present or in order to prepare for future increased variation in age in their workforce, companies should invest in two organizational intervention strategies to at least prevent the negative outcomes. First, top managers should be sensitized to the effects that their important role modelling position has on the general negative age-discrimination climate within their organization. Thus, each top manager should participate in both awareness-based trainings to allow a reflection of his or her age stereotypes and behaviour-based trainings that provide concrete recommendations on how to deal with an age diverse workforce (see Bezrukova et al., 2012 for a review on such training programmes). Wegge et al. (2012) describe an evaluated supervisor training programme that has reduced age stereotypes and age-based conflict in age diverse teams. Second, our data indicate that diversity-friendly HR policies signal the employees that their organization makes serious efforts to support diversity. Thus, companies should invest in institutional diversity management programmes, trainings, and workshops to mitigate the perceptions of discrimination and spur performance.

\section{Limitations and Future Research Directions}

Despite several strengths, as independent data sources for all central study variables, the following limitations should be considered when interpreting our results. First, the specified nature of our sample limited the generalizability of our findings, as the surveyed companies were mainly small and medium-sized and the small number of employees in most of the companies might have worked in favour of our hypotheses: the socialcategorization processes that we assume as a theoretical mechanism might be more likely to occur in small companies where employees get to know each other better beyond group and department boundaries, than in larger companies with several thousand employees and more separated departments and subsidiaries. Thus, future studies should try to replicate our results with larger companies from different cultural backgrounds. In 
addition, although we could test our hypotheses using a dataset of 147 firms from various industries, this number is still relatively low compared to strategic management research on firm performance that often uses archival data from more than 500 firms. Thus, the generalizability of our results is limited with this sample, and we encourage replications and extensions of our research in larger samples.

Second, our cross-sectional design prevented us from testing the causality of the proposed relationships. Although we provided solid theoretical arguments for age diversity being a driver of negative age-discrimination climate and performance in companies, we cannot rule out that the actual direction of influence was the other way around. We tried to solve this problem at least partly by applying numerous measures against endogeneity issues. Nonetheless, we suggest that future studies test our framework with longitudinal and quasi-experimental research designs (e.g. Shadish et al., 2002).

Third, our information on the diversity-friendly HR policies was gathered by asking only one key informant (i.e. the top HR representative) in each company, which might raise concerns regarding the accuracy and reliability of the measure (e.g. Wright et al., 2001). In addition, one potential risk is that the answers might be biased by social desirability (i.e. the HR manager had to assess his own diversity policies). However, we think that the top HR representative in a company is a good source for assessing the efforts that an organization puts into managing diversity (e.g. Avery and McKay, 2010). Nonetheless, future studies should collect other reported measures of diversity-friendly HR policies. A similar bias might have occurred for the self-reported top management age stereotypes. They are also potentially biased by social desirability to report as low of age stereotypes as possible. Furthermore, in line with most existing literature (e.g. Posthuma and Campion, 2009) our study only allows conclusions about the effects of stereotypes of the top management against older workers, not against all age groups. Consequently, future research might corroborate our findings by adding other reported stereotypes against all age groups. Additionally, it might be worthwhile to study the potential interplay between age stereotypes held by top management and those stereotypes held by lower hierarchical levels (such as line managers or the employees).

Fourth, we are aware of the potential weaknesses of subjective performance ratings, as discussed by others (Starbuck, 2004), and objective financial performance measures would in fact be the best source for company performance. However, the specific nature of our sample restricted the collection of these objective measures as the companies were mostly privately owned and thus do not publish performance results, which is the most common source for market performance measures (Rogers and Wright, 1998). Dess and Robinson (1984), however, found that subjective performance measures of the top management team were strongly correlated with objective performance of privately held companies (for similar studies, see Rowe and Morrow, 1999; Wall et al., 2004). In addition, a one- or two-year time lag between the mediator and firm performance would be ideal to better test the causal direction of influence. Thus, we hope that future studies replicate our findings with time-lagged objective performance measures.

Beyond these limitations, our research offers several interesting directions for future research. First, both moderators in this study (top managers' negative age stereotypes and diversity-friendly HR policies) at least buffered the negative effect of age diversity in companies in terms of organizational performance. However, from a practical and 
theoretical perspective, it might be even more compelling for companies to know organizational boundary conditions that enable positive effects of age diversity on company performance. Thus, future studies should intensify the search for such moderators and, for instance, investigate in more detail the role of HR practices in the age diversityperformance relationship. Although our study focused on general diversity measures to buffer the negative performance consequences of age diversity, future studies might further develop our argumentation for age-specific age-inclusive HR measures (Armstrong-Stassen and Templer, 2005; Goebel and Zwick, 2010). Such age-inclusive HR measures might be perceived as an even stronger statement by the organization to suggest that the avoidance of age discrimination in particular is a key goal of the organization, which in turn will potentially release the benefits of age diversity. A further potential context factor unlocking the potential of age diversity might be task type, as prior studies have found that age diversity was positively correlated with group performance only in groups solving complex tasks (Wegge et al., 2008).

Second, future research might also theoretically extend our findings by investigating the organizational consequences of age diversity over time. As Blau's (1977) heterogeneity theory suggests, high levels of age heterogeneity in companies might also have positive effects on social processes and performance outcomes. Blau (1977) proposed that growing heterogeneity increases the probability of intergroup relations (i.e. between old and young employees), which in turn offers the possibility for fortuitous relationships between different-aged peers, lowering mutual prejudices and ultimately discrimination. Although our results indicate exactly the opposite effects, these theoretically derived positive effects might be captured by investigating the development of age diversity in companies over time. Potentially, an increase in age diversity might first evoke the negative categorization consequences that we observe in our cross-sectional data when occurring in companies. However, if over longer time the diversity prevails on a high level, the development of positive ties between various age groups might increase, leaving room for the diffusion of positive age diversity effects.

Taken together, this study is a further attempt to understand the complex age diversity/company performance association by introducing top managers' stereotypes and diversity-friendly HR policies as important contingent factors in that relationship. We hope this research will encourage other scholars to continually investigate consequences and solutions for the demographic change in companies.

\section{AGKNOWLEDGMENTS}

We thank the editor Don Bergh and three anonymous reviewers for their constructive and helpful comments in the review process of this article. We also acknowledge the feedback and support from Torsten Biemann, Simon de Jong, and Alexander Himme during the development of the article. Finally, we gratefully acknowledge the financial support of the Hans-Boeckler Foundation from Germany.

\section{NOTES}

[1] As a robustness check for a potential non-response bias, we reran our analyses excluding those companies with a very low $(<30$ per cent) response rate $(n=10)$. Since that did not change the overall pattern of our results, we assume a very low likelihood of a non-response bias for our analyses. 
[2] As we had only one respondent per company for these measures, we did not apply listwise deletion techniques for missing values, but decided to follow the advice by Enders and Bandalos (2001), who favour both pairwise deletion and full information maximum likelihood (FIML) techniques over listwise deletion. Thus, we ran all of our SEM analyses using first a covariance matrix based on pairwise deletion techniques and then with raw data that used the FIML technique, which resulted in similar results. We based the overall reporting of our results on the pairwise deletion techniques because, in contrast to FIML, they allow us to run bootstrapping analyses, which are necessary for testing our moderatedindirect hypotheses.

[3] To inspect the robustness of our results we reran all our analyses with age diversity operationalized by the coefficient of variance, the mean Euclidean distance, as well as a bias corrected version of the standard deviation (Biemann and Kearney, 2010), which all resulted in similar results. Detailed results of these analyses are available upon request from the first author.

[4] Although an $\mathrm{ICG}_{1}$ of 5 per cent is relatively low, Bliese (1998) argued that it is still justified to aggregate, because even if only 1 per cent of the variance can be attributed to group/company membership, substantial group level effects may exist (see also Cole et al., 2011).

\section{APPENDIX}

Shared perception of negative age-discrimination climate (Kunze et al., 2011)

1. Age-discriminatory behaviour regarding job assignments exists in our company

2. Age-discriminatory behaviour regarding opportunities for individual promotion exists in our company

3. Age-discriminatory behaviour regarding performance evaluation exists in our company

4. Age-discriminatory behaviour regarding opportunities for personal and professional development of employees exists in our company

5. Age-discriminatory behaviour in the daily leadership of the seniors exists in our company

Top managers' negative age stereotypes (Chiu et al., 2001)

1. Older workers are not interested in learning new skills

2. Older workers do not work as hard as other employees

3. Most older workers cannot keep up with the speed of modern industries

Diversity-friendly HR policies (Triana and García, 2009)

1. Our organization sponsors classes, workshops, and/or seminars on diversity

2. Our company puts a lot of effort into diversity management

3. Our company spends enough money and time on diversity awareness and related trainings

\section{Organizational performance}

Please assess the performance of your company compared to your main competitors in the same industry since the beginning of this year on the following dimensions:

1. Financial situation

2. Company growth

3. Employee productivity

4. Employee fluctuation and retention

\section{REFERENGES}

Abraham, J. D. and Hansson, R. O. (1995). 'Successful aging at work: an applied study of selection, optimization, and compensation through impression management'. Fournals of Gerontology Series B, 50, 94-103.

Aiken, L. S. and West, G. (1991). Multiple Regressions: Testing and Interpreting Interactions. Thousand Oaks, CA: Sage.

Anderson, J. C. and Gerbing, D. W. (1988). 'Structural equation modeling in practice: a review and recommended two-step approach'. Psychological Bulletin, 103, 411-23.

Antonakis, J., Bendahan, S., Jacquart, P. and Lalive, R. (2010). 'On making causal claims: a review and recommendations'. Leadership Quarterly, 21, 1086-120. 
Armstrong-Stassen, M. (2008). 'Organisational practices and the post-retirement of older workers'. Human Resource Management Fournal, 18, 36-53.

Armstrong-Stassen, M. and Templer, A. (2005). 'Adapting training for older employees'. Fournal of Management Development, 24, 57-67.

Aubert, P. and Crepon, B. (2006). Age, Wage and Productivity: Firm Level Evidence. Discussion Paper, INSEE, Paris.

Avery, D. R. and McKay, P. F. (2010). 'Doing diversity right: an empirically based approach to effective diversity management'. In Hodgkinson, G. P. and Ford, J. K. (Eds), International Review of Industrial and Organizational Psychology. New York: Wiley, 227-52.

Backes-Gellner, U. and Veen, S. (2009). The Impact of Aging and Age Diversity on Company Performance. SSRN Working Paper, University of Zurich, Zurich.

Baltes, B. B. and Finkelstein, L. M. (2011). 'Contemporary empirical advancements in the study of aging in the workplace'. Fournal of Organizational Behavior, 32, 151-4.

Bantel, K. A. and Jackson, S. E. (1989). 'Top management and innovations in banking - does the composition of the top management make a difference'. Strategic Management Fournal, 10, 107-24.

Bentler, P. M. (2007). 'On tests and indices for evaluating structural models'. Personality and Individual Differences, 42, 825-9.

Bezrukova, K., Jehn, K. A. and Spell, C. S. (2012). 'Reviewing diversity training: where we have been and where we should go'. Academy of Management Learning \& Education, 11, 207-27.

Biemann, T. and Kearney, E. (2010). 'Size does matter: how varying group sizes in a sample affect the most common measures of group diversity'. Organizational Research Methods, 13, 582-99.

Blau, P. M. (1964). Exchange and Power in Social Life. Rutgers, NJ: Transaction Publishers.

Blau, P. (1977). Inequality and Heterogeneity. New York: Free Press.

Bliese, P. D. (1998). 'Group size, ICG values, and group-level correlations: a simulation'. Organizational Research Methods, 1, 355-73.

Bliese, P. D. (2000). 'Within group agreement, non-independence, and reliability'. In Klein, K. J. and Kozlowski, S. W. (Eds), Multilevel Theory, Research, and Methods in Organizations. San Francisco, CA: Jossey-Bass, 349-81.

Börsch-Supan, A. and Wilke, C. B. (2009). 'Zur mittel-und langfristigen Entwicklung der Erwerbstätigkeit in Deutschland'. Fournal for Labour Market Research, 42, 29-48.

Brooke, L. and Taylor, P. (2005). 'Older workers and employment: managing age relations'. Ageing and Society, 25, 415-29.

Browne, M. and Cudeck, R. (1993). 'Alternate ways of assessing model fit'. In Bollen, K. A. and Long, J. S. (Eds), Testing Structural Equation Models. Newbury Park, CA: Sage, 136-62.

Bryne (1971). The Attraction Paradigm. New York: Academic Press.

Burke, M. J., Finkelstein, L. M. and Dusig, M. S. (1999). 'On average deviation indices for estimating interrater agreement'. Organizational Research Methods, 2, 49-68.

Butler, R. N. (1969). 'Ageism: another form of bigotry'. The Gerontologist, 9, 243-46.

Capowski, G. and Peak, M. H. (1994). 'Ageism: the new diversity issue'. Management Review, 83, 10-5.

Carmeli, A. (2008). 'Top management team behavioral integration and the performance of service organizations'. Group \& Organization Management, 33, 712-35.

Carmeli, A. and Schaubroeck, J. (2006). 'Top management team behavioral integration, decision quality, and organizational decline'. Leadership Quarterly, 17, 441-53.

Cheung, G. W. and Lau, R. S. (2008). 'Testing mediation and suppression effects of latent variables: bootstrapping with structural equation models'. Organizational Research Methods, 11, 296-325.

Chiu, G. K., Chan, A. W., Ed, S. and Redman, T. (2001). 'Age stereotypes and discriminatory attitudes towards older workers: an East-West comparison'. Human Relations, 54, 629-61.

Cole, M. S., Bedeian, A. G., Hirschfeld, R. R. and Vogel, B. (2011). 'Dispersion-composition models in multilevel research: a data-analytic framework'. Organizational Research Methods, 14, 718-34.

Combs, J. G., Crook, T. R. and Shook, C. L. (2005). 'The dimensionality of organizational performance and its implications for strategic management research'. Research in Social Stratification and Mobility, 2, 259-86.

Dess, G. G. and Robinson, R. B. (1984). 'Measuring organizational performance in the absence of objective measures: the case of the privately held firm and conglomerate business unit'. Strategic Management Journal, 5, 265-73.

Duncan, C., Loretto, W. and White, P. (2000). 'Ageism, early exit, and British trade unions'. Industrial Relations fournal, 31, 220-34.

Dychtwald, K., Erickson, T. and Morison, B. (2004). 'It's time to retire retirement'. Harvard Business Review, 82, $48-57$. 
Enders, C. K. and Bandalos, D. L. (2001). 'The relative performance of full information maximum likelihood estimation for missing data in structural equation models'. Structural Equation Modeling, 8, $430-57$.

European Commission (2009). Discrimination in the EU in 2009. Brussels.

Ferris, G. R., Frink, D. D. and Galang, M. C. (1993). 'Diversity in the workplace: the human resources management challenges'. Human Resource Planning, 16, 41-51.

Finkelstein, L. M., Burke, M. J. and Raju, N. S. (1995). 'Age discrimination in simulated employment contexts: an integrative analysis'. Fournal of Applied Psychology, 80, 652-63.

Fiske, S. T. (2004). 'Stereotyping, prejudice, and discrimination: social biases'. In Fiske, S. T. (Ed.), Social Beings: A Core Motives Approach to Social Psychology. Hoboken, NJ: Wiley, 397-457.

Garcia-Prieto, P., Bellard, E. and Schneider, S. C. (2003). 'Experiencing diversity, conflict, and emotions in teams'. Applied Psychology, 52, 413-40.

Goebel, C. and Zwick, T. (2009). Age and Productivity - Evidence from Linked Employer Employee Data. ZEW Discussion Paper No. 09-020.

Goebel, C. and Zwick, T. (2010). Which Personnel Measures are Effective in Increasing Productivity of Old Workers? ZEW Discussion Paper No. 10-069.

Gouldner, A. W. (1960). 'The norm of reciprocity: a preliminary statement'. American Sociological Review, 25, $161-78$.

Greene, W. H. (2008). Econometric Analysis. Upper Saddle River, NJ: Prentice Hall.

Grund, C. and Westergaard-Nielsen, N. (2008). 'Age structure of the workforce and firm performance'. International Fournal of Manpower, 29, 410-22.

Gutek, B. A., Cohen, A. G. and Tsui, A. (1996). 'Reactions to perceived sex discrimination'. Human Relations, 49, 791-813.

Hambrick, D. C. and Mason, P. A. (1984). 'Upper echelons: the organization as a reflection of its top managers'. Academy of Management Review, 9, 193-206.

Hambrick, D. C., Cho, T. S. and Chen, M. J. (1996). 'The influence of top management team heterogeneity on firms' competitive moves'. Administrative Science Quarterly, 41, 659-84.

Hamilton, D. L. and Sherman, J. W. (1994). 'Stereotypes'. In Weyer, R. S. and Srull, T. K. (Eds), Handbook of Social Cognition. Mahawa, NJ: Lawrence Erlbaum, 1-68.

Harrison, D. A. and Klein, K. J. (2007). 'What's the difference? Diversity constructs as separation, variety, or disparity in organizations'. Academy of Management Review, 32, 1199-228.

Hassell, B. L. and Perrewe, P. L. (1993). 'An examination of the relationship between older workers' perceptions of age discrimination and employee psychological states'. Fournal of Managerial Issues, $\mathbf{5}$, $109-20$.

Hicks-Clarke, D. and Iles, P. (2000). 'Climate for diversity and its effects on career and organisational attitudes and perceptions'. Personnel Review, 29, 324-45.

Horwitz, S. K. and Horwitz, I. B. (2007). 'The effects of team diversity on team outcomes: a meta-analytic review of team demography'. Fournal of Management, 33, 987-1015.

Hu, L. and Bentler, P. M. (1998). 'Fit indices in covariance structure modeling: sensitivity to underparameterized model misspecification'. Psychological Methods, 3, 424-53.

Hulland, J. (1999). 'Use of partial least squares (PLS) in strategic management research: a review of four recent studies'. Strategic Management Journal, 20, 195-204.

Hutchison, S., Sowa, D., Eisenberger, R. and Huntington, R. (1986). 'Perceived organizational support'. Fournal of Applied Psychology, 71, 500-7.

Ilmakunnas, P. and Ilmakunnas, S. (2011). 'Diversity at the workplace: whom does it benefit?'. De Economist, 159, $1-33$

Ilmakunnas, P., Maliranta, M. and Vainiomäki, J. (2004). 'The roles of employer and employee characteristics for plant productivity'. Fournal of Productivity Analysis, 21, 249-76.

Jonker, B. and Ziekemeyer, M. (2005). 'Wake up call - human resource management (HRM): an orientation on company models anticipating ageing'. International Congress Series, 1280, 371-6.

Joshi, A. and Roh, H. (2009). 'The role of context in work team diversity research: a meta-analytic view'. Academy of Management fournal, 52, 599-627.

Kanfer, R. and Ackerman, P. L. (2004). 'Aging, adult development, and work motivation'. Academy of Management Review, 29, 440-58.

Kilduff, M., Angelmar, R. and Mehra, A. (2000). 'Top management-team diversity and firm performance: examining the role of cognitions'. Organization Science, 11, 21-34.

Kunze, F., Boehm, S. and Bruch, H. (2011). 'Age diversity, age discrimination, and performance consequences - a cross organizational study'. Fournal of Organizational Behavior, 32, 264-90. 
Lawrence, B. S. (1984). 'Age grading: the implicit organizational timetable'. Fournal of Occupational Behavior, $\mathbf{5}$, 23-35.

Lawrence, B. S. (1988). 'New wrinkles in the theory of age: demography, norms, and performance ratings'. Academy of Management Fournal, 31, 309-37.

Leonard, J. S. and Levine, D. I. (2003). Diversity, Discrimination, and Performance. IIRUPS Working Paper 091-03, University of California Berkeley, Berkeley.

Levy, B. R., Zonderman, A. B., Slade, M. D. and Ferrucci, L. (2012). 'Memory shaped by age stereotypes over time'. Fournals of Gerontology Series B, 67, 432-36.

Little, T. D., Bovaird, J. A. and Widaman, K. F. (2006). 'On the merits of orthogonalizing powered and product terms: implications for modeling latent variable interactions'. Structural Equation Modeling, 13, $479-519$.

Maitlis, S. (2005). 'The social processes of organizational sensemaking'. Academy of Management Fournal, 48 , 21-49.

Miller, T. and Triana, M. D. (2009). 'Demographic diversity in the boardroom: mediators of the board diversity-firm performance relationship'. Fournal of Management Studies, 46, 755-86.

O'Brien, L. T. and Hummert, M. L. (2006). 'Memory performance of late middle-aged adults: contrasting self-stereotyping and stereotype threat accounts of assimilation to age stereotypes'. Social Cognition, 24, $338-58$.

Ostroff, C. and Atwater, L. E. (2003). 'Does whom you work with matter? Effects of referent group gender and age composition on managers' compensation'. Fournal of Applied Psychology, 88, 72540.

Pierce, J. L. and Gardner, D. G. (2004). 'Self-esteem within the work and organizational context: a review of the organization-based self-esteem literature'. Fournal of Management, 30, 591-622.

Podsakoff, P. M., MacKenzie, S. B., Lee, J. Y. and Podsakoff, N. P. (2003). 'Common method biases in behavioral research: a critical review of the literature and recommended remedies'. Fournal of Applied Psychology, 88, 879-903.

Posthuma, R. A. and Campion, M. A. (2009). 'Age stereotypes in the workplace: common stereotypes, moderators, and future research directions'. Fournal of Management, 35, 158-88.

Preacher, K. J., Rucker, D. D. and Hayes, A. F. (2007). 'Addressing moderated mediation hypotheses: theory, methods, and prescriptions'. Multivariate Behavioral Research, 42, 185-227.

Richardson, H. A. and Vandenberg, R. J. (2005). 'Integrating managerial perceptions and transformational leadership into a work-unit level model of employee involvement'. Fournal of Organizational Behavior, 26, 561-89.

Ries, B. C., Diestel, S., Wegge, J. and Schmidt, K. H. (2010). 'Die Rolle von Alterssalienz und Konflikten in Teams als Mediatoren der Beziehung zwischen Altersheterogenität und Gruppeneffektivität'. Zeitschrift Für Arbeits-Und Organisationspsychologie, 54, 117-30.

Robinson, G. and Dechant, K. (1997). 'Building a case for diversity'. Academy of Management Executive, 11, 21-31.

Rogers, E. W. and Wright, P. M. (1998). 'Measuring organizational performance in strategic human resource management: problems, prospects and performance information markets'. Human Resource Management Review, 8, 311-31.

Rowe, W. G. and Morrow, J. L. (1999). 'A note on the dimensionality of the firm financial performance construct using accounting, market and subjective measures'. Canadian fournal of Administrative Science, $\mathbf{1 6}$, $58-70$.

Salanova, M., Agut, S. and Peiro, J. M. (2005). 'Linking organizational resources and work engagement to employee performance and customer loyalty: the mediation of service climate'. Fournal of Applied Psychology, 90, 1217-27.

Schneider, B. (1987). 'The people make the place'. Personnel Psychology, 40, 437-53.

Shadish, W., Cook, T. and Campbell, D. (2002). Experimental and Quasi-Experimental Designs for Generalized Causal Inference. Boston, MA: Houghton Mifflin.

Shore, L. M. and Wayne, S. J. (1993). 'Commitment and employee behavior: comparison of affective and continuance commitment with perceived organizational support'. Fournal of Applied Psychology, 78, 774-80.

Simons, T., Pelled, L. H. and Smith, K. A. (1999). 'Making use of difference: diversity, debate, and decision comprehensiveness in top management teams'. Academy of Management Fournal, 42, 66273.

Skirbekk, V. (2008). 'Age and productivity capacity: descriptions, causes and policy options'. Ageing Horizons, 8, $4-12$. 
Smith, K. G., Smith, K. A., Olian, J. D., Sims Jr, H. P., O’Bannon, D. P. and Scully, J. A. (1994). 'Top management team demography and process: the role of social integration and communication'. Administrative Science Quarterly, 39, 412-38.

Snape, E. and Redman, T. (2003). 'Too old or too young? The impact of perceived age discrimination'. Human Resource Management fournal, 13, 78-89.

Staiger, D. and Stock, J. H. (1997). 'Instrumental variables regression with weak instruments'. Econometrica, 65, 557-86.

Starbuck, W. H. (2004). 'Methodological challenges posed by measures of performance'. Fournal of Management and Governance, 8, 337-43.

Stock, J. H., Wright, J. H. and Yogo, M. (2002). 'A survey of weak instruments and weak identification in generalized method of moments'. Fournal of Business and Economic Statistics, 20, 518-29.

Tajfel, H. (1970). 'Experiments in intergroup discrimination'. Scientific American, 223, 96-102.

Tajfel, H. and Turner, J. C. (1986). 'The social identity theory of intergroup behaviour'. In Worchel, S. and Austin, W. G. (Eds), Psychology of Intergroup Relation. Chicago, IL: Nelson-Hall, 7-24.

Thomas, D. A. and Ely, R. J. (1996). 'Making differences matter'. Harvard Business Review, 74, 79-90.

Tougas, F. and Veilleux, F. (1989). 'Who likes affirmative action: attitudinal processes among men and women'. In Blanchard, F. A. and Crosby, F. (Eds), Affirmative Action in Perspective. New York: Springer, $111-24$.

Triana, M. G. and García, M. F. (2009). 'Valuing diversity: a group value approach to understanding the importance of organizational efforts to support diversity'. Fournal of Organizational Behavior, 30, 941-62.

Triana, M. C., Garcia, M. F. and Colella, A. (2010). 'Managing diversity: how organizational efforts to support diversity moderate the effects of perceived racial discrimination on affective commitment'. Personnel Psychology, 63, 817-43.

Tsui, A. S., Porter, L. W. and Egan, T. D. (2002). 'When both similarities and dissimilarities matter: extending the concept of relational demography'. Human Relations, 55, 899-929.

Turner, J. C. (1985). 'Social categorization and the self-concept: a social cognitive theory of group behavior'. In Lawler, E. J. (Ed.), Advances in Group Processes: Theory and Research. Greenwich, GT: JAI Press, 77-122.

van Knippenberg, D. and Schippers, M. C. (2007). 'Work group diversity'. Annual Review of Psychology, 58, 515-41.

Wall, T. D., Michie, J., Patterson, M., Wood, S. J., Sheehan, M., Clegg, C. W. and West, M. (2004). 'On the validity of subjective measures of company performance'. Personnel Psychology, 57, 95-118.

Wegge, J., Roth, G., Neubach, B., Schmidt, K. H. and Kanfer, R. (2008). 'Age and gender diversity as determinants of performance and health in a public organization: the role of task complexity and group size'. Fournal of Applied Psychology, 93, 1301-13.

Wegge, J., Jungmann, F., Schmidt, K.-H. and Liebermann, S. (2011). 'Das Miteinander der Generationen am Arbeitsplatz'. Iga Report, 21, 64-97.

Wegge, J., Jungmann, F., Liebermann, S., Shemla, M., Ries, B., Diestel, S. and Schmidt, K. H. (2012). 'What makes age diverse teams effective? Results from a six-year research program'. Work, 41, $5145-51$.

Wrenn, K. A. and Maurer, T. J. (2004). 'Beliefs about older workers' learning and development behavior in relation to beliefs about malleability of skills, age-related decline, and control'. Fournal of Applied Social Psychology, 34, 223-42.

Wright, P. M., Gardner, T. M., Moynihan, L. M., Park, H. J., Gerhart, B. and Delery, J. E. (2001). 'Measurement error in research on human resources and firm performance: additional data and suggestions for future research'. Personnel Psychology, 54, 875-902.

Zenger, T. R. and Lawrence, B. S. (1989). 'Organizational demography: the differential effects of age and tenure distributions on technical communication'. Academy of Management fournal, 32, 353-76. 